\title{
ARTIGO
}

\section{Ensinar e aprender: reflexões acerca da pesquisa em Ciência da Informação}

\author{
Teaching and learning: reflections concerning \\ research within Information Science
}

Virginia Bentes PINTO ${ }^{1}$

Edna Gomes PINHEIRO²

\section{RE S U M O}

Discute alguns aspectos relativos aos conceitos de pesquisa e suas formas de abordagem -quantitativas, qualitativas e mistas-, apresentando a sócio-poética e o método criativo sensível como alternativas metodológicas para a Ciência da Informação e a Biblioteconomia. Aponta ainda as possíveis causas das dificuldades que os acadêmicos enfrentam no ato de pesquisar, finalizando com algumas reflexões acerca do ensinar e do aprender a pesquisar.

Palavras-chave: pesquisa, abordagens de pesquisa, sócio-poética, escuta sensível.

\section{A B S T R A C T}

Discusses some of the aspects related to the research concepts and their forms of quantitative, qualitative, and mixed approach, presenting the socio-poetics and the sensitive creative approach, as methodological alternatives to be used

\footnotetext{
1 Professora, Doutora, Departamento de Ciências da Informação, Universidade Federal do Ceará. Av. da Universidade, 2762, 10 andar, Benfica, 60080-120, Fortaleza, CE, Brasil. Correspondência para/Correspondenceto: V.B. PINTO. E-mail: vbentes@ufc.br 2 Professora, Departamento de Biblioteconomia e Documentação, Universidade Fedral da Paraíba. Cidade Universitária, Campus I, 58000-000, João Pessoa, PB, Brasil. E-mail: ednapi@bol.com.br Recebido em 22/4 e aceito para publicação em 11/8/2003.
} 
in the Information Science and Library studies. It also points to the possible causes of the difficulties confronted by academics in the research practice, finalizing with some reflections concerning teaching and learning how to research.

Key-words: research, research approaches, socio-poetics, receptive hearing.

\section{N T R O D U Ç Ã O}

Com o tema geral "As Articulações da Pesquisa com o Ensino e a Extensão nos Cursos de Biblioteconomia do Mercosul" a ABECIN traz à tona, em tempo hábil, a discussão de questões atuais envolvendo o tripé da universidade: ensino, pesquisa e extensão no âmbito da Ciência da Informação e da Biblioteconomia. Este fato não pode ser mais ignorado, uma vez que os cursos existentes no Brasil, principalmente nas escolas públicas seguem tal modelo. No entanto, mexer com "articulação", não é tarefa simples e muito menos fácil de se trabalhar, seja no campo da fisiologia, da política, ou da educação, pois requer um certo jeito para que o ato de articular não venha a ser traumático para os envolvidos no processo, daí a necessidade de uma mídia humana como elemento articulador. No contexto acadêmico o professor, além de educador, é também um articulador.

Ao longo do tempo encontrar o jeito certo de articular a pesquisa com o ensino e a extensão, tornou-se uma preocupação constante para nós professores, pesquisadores, orientadores e co-orientadores em trabalhos de conclusão de cursos de graduação e pós-graduação (especialização e mestrado), na iniciação cientifica, em projetos de extensão e em ministrar cursos e oficinas nesta área. E, justamente por atuarmos neste metié, por escutarmos as dificuldades de quem está iniciando no campo da pesquisa e, conversando com nossos pares, é que nos sentimos encorajadas a escrever este trabalho na perspectiva de mostrar que tanto a fase exploratória da pesquisa, quanto às de coleta, análise ou tratamento dos dados, como a da organização estrutural da redação dos relatórios e monografias, demandam um certo rigor. E, é exatamente este rigor, para muitos, o responsável pelos traumas, impasses e conflitos dos noviços na iniciação científica. Esse processo nevrálgico, muitas vezes, instiga o medo e a insegurança, transformando o ato de pesquisar, logo na escolha do tema, em momentos de angústia e sofrimento para os principiantes levando-os, em muitos casos, ao abandono, mesmo que efêmero da feitura dos projetos e das monografias.

É na perspectiva de tratar algumas questões da pesquisa e de seu ensino que, neste momento de revisão e atualização das nossas utopias de educadores, comprometidos com o ato de articular que desenvolvemos estas reflexões, acreditando na possibilidade de construir um projeto coletivo onde seja possível termos clara a compreensão do que venha a ser a pesquisa, seus elementos, suas várias abordagens, seus vários métodos e o desenvolvimento dos recursos metodológicos da pesquisa em Ciência da Informação, ainda tão pouco explorado, embora de suma importância: a das abordagens qualitativas.

\section{COM PREEN DENDOA TEIA DA PESQUISA}

A palavra pesquisa, como muitas outras da língua portuguesa, é bastante polissêmica, portanto, seu conceito não pode ser percebido de forma unívoca. Esta palavra chegou ao português, emprestada do espanhol, mas sua origem vem do verbo latim perquiro cujo significado está associado a procurar, buscar e investigar de forma cuidadosa. Neste sentido, podemos considerar que esse conceito faz parte 
do nosso cotidiano quando pesquisamos preços, qualidade, locais de eventos, emprego entre outros. No entanto é preciso ter-se bem clara a diferença entre este processo investigativo e a pesquisa voltada para a compreensão, a construção e o avanço da ciência, ou seja, a pesquisa científica. Neste caso, a pesquisa pode ser entendida como uma investigação sistemática sobre determinada realidade, apoiada em uma metodologia coerente que vise a explicação e/ou a resolução de um problema, sendo desenvolvida com rigor científico e de acordo com o ritmo individual de cada pesquisador.

Beillerot (1991) trabalha muito bem essas ambigüidades mostrando que o campo da pesquisa pode ser analisado do ponto de vista de être en recherch (estar em pesquisa), faire de la recherche e faire des recheches (fazer pesquisa(s) e être chercheu (ser pesquisador). Assim o autor se expressa:

Nos meios universitários, o uso da palavra pesquisa no singular $e$ às vezes com uma inicial maiúscula, implica um subentendido carregado de sentido, de equívocos e conivências: na universidade, a pesquisa é científica, ou não é (pesquisa). Gostaríamos de mostrar que a situação real não obedece a essa idéia geral e que os debates em curso..., necessitam imperativamente que se tente fazer clarificações (BEILLEROT, 1991, p. 17)

Continuando sua reflexão Beillerot (1991), propõe alguns critérios considerados fundamentais para a atividade de pesquisa:

Pesquisa de nível 'mínima': é pautada nos processos e na atividade mental, o que implicaria em três condições: produção de conhecimentos novos, procedimento de investi-gação rigoroso, comunicação dos resultados.
Até aqui, tudo bem, são os critérios que atendem as exigências gerais da ciência. Embora o autor reconheça as dificuldades para colocá-los em prática, na realidade tais critérios, se observados, viriam tanto ratificar como eliminar outras atividades denominadas indevidamente de pesquisa e ao mesmo tempo admitir outras não consideradas como tal.

Pesquisa de 'segundo grau': apóia-se na dimensão crítica e reflexiva sobre suas fontes, seus métodos e modos de trabalho, a sistematização da coleta de dados, a presença de interpretação de acordo com as teorias reconhecidas e atuais, que contribuiriam para a elaboração da problemática e a interpretação de dados, que na pesquisa de nível mínimo nem sempre ocorre.

Em suas reflexões o autor vai mais além, chamando a atenção para o cuidado com a palavra pesquisa reservando-a não somente

[...] às investigações que aplicam a totalidade dos critérios, mas será conveniente perguntar a cada uma delas a qual das séries obedece, pois mesmo atendendo apenas quatro ou cinco critérios uma pesquisa candidata ao segundo grau permanece uma pesquisa mínima, ao passo que uma outra candidata ao nível mínimo, se não preencher suas três condições simplesmente não será pesquisa (BEILLEROT, 1991, p. 23).

Nesta mesma linha de pensamento Demo (1994, p. 40), no livro "Pesquisa e construção do conhecimento", afirma que "pesquisa não é qualquer coisa" e para que uma produção seja considerada como pesquisa, o autor propõe cinco níveis fundamentais, a saber:

a) interpretação reprodutiva, na qual o texto é sistematizado e reproduzido de maneira fidedigna; 
b) interpretação própria, onde os textos são interpretados e ditos com outras palavras (paráfrase);

c) reconstrução, toma-se um texto como base e se refaz um outro de acordo com as nossas propostas, como por exemplo nas dissertações de mestrado;

d) construção, parte-se do que existe apenas como referência e a partir daí, abrem-se novos caminhos e alternativas, por exemplo, as teses de doutorado, e outros textos que apresentem novas teorias;

e) criação/descoberta de novos paradigmas metodológicos, teóricos ou práticos, consideramos aqui os cientistas.

Embora esses níveis sejam apresentados de maneira independente, na realidade, na construção de uma pesquisa, alguns desses critérios perpassam por outros. Por exemplo, a sistematização do trabalho, sua qualidade, as intervenções inovadoras e a ética. Portanto, a compreensão da pesquisa científica vai além de certos procedimentos metodológicos, embora eles façam parte deste processo. Corroborando, Goldenberg (2001) afirma que pesquisa científica exige

Criatividade, disciplina, organização e modéstia, baseando-se no confronto permanente entre possível e o impossível, entre o conhecimento e a ignorância. Nenhuma pesquisa é totalmente controlável, com início meio e fim previsíveis. A pesquisa é um processo em que é impossível prever todas as etapas. O pesquisador está sempre em estado de tensão porque sabe que seu conhecimento é parcial e limitado o possível para ele (GOLDENBERG, 2001, p.13).
A partir dessas reflexões, entendemos que nas ciências humanas a pesquisa científica é uma prática social que exige certa flexibilidade e envolvimento prazeroso dos atores deste processo. Portanto, de acordo com Gauthier et al. (2001), é uma construção contextualizada envolvendo relações sociais de "poder-saberprazer-fazer instituídas ou instituintes", em toda a sua ação pragmática.

\section{AS A BORDAGENS DE PESQUISA}

As discussões acerca das abordagens quantitativas e qualitativas de pesquisas são alimentadas por vários estudiosos do assunto, tanto em suas reflexões teóricas quanto em suas práticas. Essa dicotomia, muitas vezes, pode ser responsável por resultados distorcidos de pesquisas, pois, na tentativa de se fazer esta separação pode-se ignorar informações que complementariam as interpretações do objeto estudado, sejam eles mais voltados para investigar questões que levam em conta a objetividade ou a subjetividade e que poderiam ter uma contribuição para a interpretação da realidade observada. Corroborando, Gurvitch (1955), mostra a necessidade de se fazer diferença entre o que ele denomina de "regiões visíveis" (objetivas-quantitativas) como morfológica, ecológica, área concreta, as quais são expressas em equações, médias, gráficos e estatísticas e o "universo de significações", motivos, aspirações, atitudes, crenças e valores (subjetivos-qualitativos) os quais necessitam de um referencial de dados e produção de sentidos. Por isso, o autor adverte sobre o cuidado com essa dicotomia e afirma que os dados quantitativos e, qualitativos são interdependentes e, interagem e, por isto, não devem ser vistos como coisas isoladas e dicotômicas.

Portanto, a oposição quantitativa $x$ qualitativa é uma falha da metodologia, sendo possível a utilização dessas duas abordagens no seio de uma pesquisa, daí o surgimento de 
uma outra abordagem: a mista, que parece ser mais coerente.

A abordagem quantitativa procura tratar com a objetividade da realidade estudada e seus fundamentos se apoiam nos princípios positivistas clássicos segundo os quais:

a) O mundo social funciona de acordo com as leis causais.

b) A ciência é pautada sobre a observação sensorial.

c) A realidade consiste em estruturas e instituições identificáveis tanto como dados brutos quanto um imaginário representativo de crenças e valores, ambos correlacionados a fim de, fornecer generalizações e regularidade.

d) Os dados brutos são considerados reais e objetivos enquanto que, os valores e crenças são realidades subjetivas e sua compreensão somente é possível através dos dados brutos (HUGHES, 1983, p.42).

No entanto tratando-se das Ciências Humanas a linearidade da objetividade parece ser de difícil aplicação, em virtude de seu objeto de estudo estar focado no ser humano com toda a sua riqueza de subjetividade. Portanto como assevera Minayo (1993)

Os dados relativos à realidade social seriam objetivos se produzidos por instrumentos padronizados, visando eliminar fontes de propensões de todos os tipos e a apresentar uma linguagem observacional neutra. A linguagem das variáveis fornecia a possibilidade de expressar generalizações com precisão e objetividade (MINAYO, 1993, p. 30).

A aplicabilidade desta abordagem no campo da Ciência da Informação e da Biblioteconomia pode ser explicada pela dificuldade que o profissional tem em compreender o valor de sua atividade profissional como um trabalhador da informação, independente do suporte e da forma como ela se apresenta e do espaço arquitetônico onde ela esteja armazenada e, de demonstrar este valor para a sociedade, para o setor produtivo empresarial e comercial (como empregadores). Isto pode ainda ser entendido como o reflexo da história da construção da área onde as pesquisas mostram que inicialmente os estudos estavam muito mais voltados para a solução de problemas práticos. Portanto, a abordagem quantitativa poderia apresentar-se como uma estratégia de pesquisa mais fácil de ser demonstrada e compreendida. No entanto, a partir das últimas décadas observa-se maior tendência de pesquisas utilizando a abordagem qualitativa e mista.

A abordagem qualitativa no campo da pesquisa social teve seu ponto máximo de discussão a partir das reflexões de Thomas Khun com a sua "crise dos paradigmas", que trouxe à tona as questões da objetividade e racionalidade da ciência, questões estas que vinham de encontro às propostas positivistas de Augusto Comte. Essa abordagem é pautada no pensar a realidade estudada visando a sua compreensão e a sua descrição de modo rigoroso, onde o pesquisador busca produzir sentidos a partir dos discursos dos sujeitos envolvidos na pesquisa, entendendo o indivíduo como a parte ativa no processo de investigação e, permitindo-lhe a interferência com maior profundidade nas respostas. Seus fundamentos estão apoiados na fenomenologia enquanto base filosófica para a compreensão da realidade. Asseverando, Serpa (1991, p.14) diz que "conhecer um objeto significa explicitar a sua essência, a partir de observações sobre as suas qualidades." Nas palavras de Santos (1996, p.15) significa "dividir e classificar, para depois poder determinar relações sistemáticas entre o que se separou."

Nessa abordagem o pesquisador não se fecha em uma camisa de força nem para a coleta nem para a análise dos dados, podendo ser mais livre e criativo. Esta nossa compreensão pode 
levar a várias interpretações e ao imaginário de que os adeptos desta abordagem trabalham em um "pseudo-anarquismo científico" o que não é verdade, haja vista que o pesquisador pode empregar técnicas diferentes de coleta de dados que já foram experimentadas, comparar seus resultados com os da literatura e apresentar pesquisas com resultados muito mais interessantes. Ora, na abordagem qualitativa se faz necessário situar o fenômeno. No caso da Ciência da Informação e da Biblioteconomia o fenômeno informação está diretamente associado com a presença do ser humano, desde a produção até a sua recuperação e recepção. Portanto, o pesquisador deste domínio deve estar interessado no ser humano enquanto produtore consumidor de conhecimentos e informações.

A abordagem mista de pesquisa surgiu como o elemento mediador entre quantitativo e qualitativo. Para Goldenberg (2001, p. 62) a integração destas duas abordagens "permite que o pesquisador faça um cruzamento de suas conclusões, de modo a ter maior confiança que seus dados não são produto de um procedimento específico ou de alguma situação particular", não se limitando a apenas um instrumento de coleta dos dados mas vários: questionário, entrevista, observação, análise de conteúdo, dados estatísticos etc, fenômeno entendido como "triangulação".

Não pretendemos aqui proceder a uma discussão exaustiva das diferentes abordagens metodológicas, porque não acreditamos nessa oposição. Acreditamos sim, que independente de utilizarmos estruturas, normas e formas tradicionais ou mais recentes, o pesquisador deve seguir o rigor do trabalho científico, no que se refere a acuidade e veracidade das informações que vai obtendo, ou melhor construindo. $O$ pesquisador deve se preocupar em colocar nessa construção toda inteligência, habilidade técnica e uma pitada de paixão, emoção para temperar.

Várias são as pesquisas que se enquadram nas abordagens qualitativas sendo as mais conhecidas: o estudo de caso, a pesquisa etnográfica, a pesquisa-ação, a pesquisa participante e que já estão sendo contempladas nas pesquisas do domínio da Ciência da Informação e da Biblioteconomia. No entanto, estamos atualmente experimentando duas novas alternativas metodológicas: o método criativo sensível e a sociopoética. Aqui, apresentaremos de forma resumida, uma vez que ambas ainda são pouco empregadas na área em lide.

\section{O MÉTODO CRIATIVO E SE N SÍ V E L}

A tônica do método está permeada de conflitos e contradições, e a questão da normatividade da ciência, através do método, revela-nos polêmica no que diz respeito à necessidade de parâmetros para pesquisar. Para ilustrar essa idéia, recorremos ao pensamento de Minayo (1993) revelando que o melhor método é aquele que permite maior aproximação com o objeto, portanto, não há sentido algum defender um método em detrimento de outro.

Tomando essa posição como norteadora, defendemos a possibilidade de que um mesmo problema pode ser resolvido por caminhos diferentes capazes de dar asas à imaginação, encontrar o deleite na visão, na compreensão e na harmonia com o mundo. Afinal, a ciência foi construída, não pela prudência dos que marcham, mas pela ousadia dos que se aventuram em trilhar novos caminhos. Talvez hoje essas considerações não nos pareçam tão estranhas, mas...nem sempre foi assim. Durante muito tempo, a concepção dominante com relação aos métodos de pesquisas, não nos permitia utilizar a força emocional como potência no pensar e no processo de produção de conhecimento. Porém, nas dobras do tempo, surge uma tendência a acreditar que não há um caminho para se entrar no conhecimento, mas vários caminhos, onde a subjetividade do pesquisador e as implicações no ato de pesquisar, não estão escondidas, mas distanciadas metodicamente. 
Nesse contexto, buscar alternativas metodológicas torna-se um desafio, sobretudo quando tentamos entender o ser humano nas suas práticas sociais, pela sua capacidade de dar sentidos diferentes a práticas semelhantes. Assim, oportunizamos analisar o método criativo sensível, a fim de contribuir para o debate no que se refere a metodologias alternativas para a Ciência da Informação. Esse método, vem sendo bastante utilizado como uma possibilidade a todo o fazer humano. Bordini e Aguiar (1988) entendem o método criativo como um meio apropriado de transformação da realidade e supõe uma relação do homem com o mundo, em que o alvo não é meramente o conhecimento do que existe, mas a exploração do existente para a produção de algo novo. Nesse sentido, arte e ciência se aproximam, enquanto que, a ciência esforça-se para instaurar e manter um discurso objetivo, subordinando-se ao saber e/ou à utilidade. No centro desse método, a criatividade, quando processada planejadamente, caracteriza-se pela aquisição de conhecimento. A raiz do processo criativo está na atitude intuitiva e subjetiva do homem que se dispõe a criar; a intuição se refere à capacidade de apreender o mundo, sem considerar o pensamento lógico, a subjetividade diz respeito à influência do sujeito sobre o objeto, adequando-o às suas necessidades.

Na visão de Bordini e Aguiar (1988), é a operação que confere uma forma a certa interação estabelecida entre o indivíduo e seus mundos externo e interno. O método criativo, conjugado com a sensibilidade, que é descrita como aquilo que mantém ligados à nossa vida contemplativa e de relação, remete-nos a Cabral (1998), que delineou o método criativo sensível, a partir das idéias de Barbier (1993), ao compreender o sensível diante do real, sob o seguinte enfoque:

[...] ao falar do sensível, diz que a sensação se afirma através dos receptores sensoriais, e a representação ligada à sensação tem um papel sobre a sensação, mas também é produzida a partir dela. Então, o que o sujeito pensa e faz traz internamente um conjunto de afetos como uma polarização em torno do prazer e do desprazer, não devendo haver um abismo entre eles. Tanto o prazer como o desprazer são sensações resultantes de estímulos internos ou externos que, ao atingir os receptores sensoriais, desencadeiam respostas de choro, dor, prazer, desprazo, dentre outras, que tomam parte na natureza humana, não devendo ser ignoradas no ato educativo e muito menos no processo de pesquisa (BARBIER, 1993, p. 195).

Essa idéia de Barbier lança luz sobre o método criativo sensível, visto que a criatividade e a sensibilidade, ao serem incorporadas a um método de pesquisa, criam uma zona de produção de dados, cuja diversidade se revela como a própria emergência do conhecimento. O referido método, portanto, ao combinar ciência e arte, espontaneidade e introspecção, realidade concreta e expressão criativa, torna-se diferente dos métodos de pesquisas instituídos e consolidados, principalmente, porque enfatiza o sujeito como um ser pessoal e social ao mesmo tempo, cuja subjetividade se manifesta no coletivo, na intersubjetividade, o que nos leva a acreditar na inexistência de uma dicotomia entre razão e os sentimentos como afeto, emoção, entre criação e sensibilidade. Corroborando com esse pensamento, Barbier (1993, p. 1888) aponta "o que o sujeito diz e pensa é reflexo de suas ações internalizadas ao longo do processo de desenvolvimento humano; ele é o somatório da sua razão e emoção; ele é sujeito porque está na relação com o outro no ambiente social". 
Compreender a sensibilidade é ver o aparente, capturar o sentido dos gestos, expressões não-verbais, cores, sons; é perceber que esses elementos são sentidos pelo olhar, pelo tato, pelo gosto, pelo cheiro, pela intuição; é saber usar essas informações para prosseguir ou não nas observações, aprofundando ou não um ponto crítico. A orientação de André (1995) sobre sensibilidade é importante na análise dos dados, porque o pesquisador não dispõe de um conjunto de procedimentos padronizados para serem seguidos passo a passo. Nesse caso, ele recorre à sua intuição, criatividade e experiência pessoal, para apreender os conteúdos, os significados, as mensagens explícitas, os valores, os sentimentos e as representações neles contidos.

Todas essas considerações surgem como propriedades da abordagem qualitativa, cercando o trabalho do pesquisador no período de coleta de dados, quando sua atenção se volta para as variáveis relacionadas ao ambiente físico, às pessoas, aos comportamentos, às instituições, às percepções e às emoções. Essa reflexão ajuda a entender que pesquisar a sensibilidade e a criatividade alheia exige do pesquisador uma atitude autocrítica, mas também flexível, criadora e sensível pois, nas Ciências Sociais, não é possível investigar a emoção com base na racionalidade. Desse modo, o método criativo e sensível, proposto por Cabral (1998), privilegia não o processo de comunicação, mas a dialogicidade intragrupal, a participação ativa na busca do conhecimento, valorizando tudo o que emerge do pensamento e da percepção do sujeito. Tem suas bases teóricas delineadas por:

a) conjugar técnicas consolidadas de coleta de dados (entrevista e observação participante) com as dinâmicas de criatividade e sensibilidade;

b) apropriar-se de diversos instrumentos de pesquisa e procedimentos da pesquisa qualitativa, tais como: roteiros de entrevistas, diário de campo, planejamento do trabalho de grupo;

c) ter no processo de criação e no empenho da sensibilidade a força produtora de dados para a pesquisa.

Conforme o esquema abordado por Bordini e Aguiar (1988, p. 71), o método criativo emerge a partir da:

a) constatação de uma carência individual ou coletiva, derivada de uma ausência comprovada, que leva o sujeito a uma decisão no sentido de supri-la;

b) coleta desordenada de dados, momento em que são oferecidas condições na tentativa de encontrar uma solução que suprimam as carências detectadas;

c) elaboração interna dos dados, momento em que os dados são aprendidos, ordenados e estruturados no nível da consciência;

d) constituição do projeto criador, etapa que prevê os esforços desenvolvidos para eliminar as carências, através de uma ação criadora;

e) elaboração do material, fase em que o insight se concretiza, realizando as etapas previstas no projeto criador. Nela os sujeitos já dominam as técnicas funcionais em relação ao material elegido;

f) divulgação do trabalho, ocasião em que os sujeitos mostraram o resultado da sua criação; a partir desse momento, os esforços deixaram de ser individuais, para converterem-se num bem comum a ser compartilhado por todos.

Em síntese, podemos expor que, para desenvolver o método criativo sensível devemos partir de duas premissas básicas. A primeira apóia-se na percepção das carências individuais ou coletivas existentes na vida dos sujeitos. Essa percepção decorre tanto das pressões vividas quanto dos sinais que o mundo oferece como respostas. Nesse rumo, a intervenção da pesquisadora se faz presente, incentivando os 
sujeitos a tomarem consciência quanto às suas carências e necessidades. O esforço desprendido nessa etapa, corresponde à proposição de várias atividades que proporcionaram condições para os pesquisandos externarem suas emoções e problemas. A segunda, incentiva os sujeitos, a tentarem dirimir suas carências, encontrando uma solução. Oferecendo os mais diversos meios para que eles, ao entrar em contato com elementos da realidade, pertinentes aos seus problemas, possam criar soluções para suprimi-los. Assim, procurando respostas às suas necessidades, os sujeitos usam a informação, gerada, disseminada e transferida, como uma ajuda nos momentos em que precisam dar sentido ou obter respostas as suas carências ou problemas. Isso nos revela, de um modo geral, que as pessoas buscam informação quando precisam de um apoio, quando se encontram num caos, padecendo aprendem o que fazer, como fazer, para dar sentido e resolver uma situação que as incomoda e clama por uma solução (DERVIN, 1989).

Conseqüentemente, ao buscar respostas para as suas carências, os sujeitos só recolhem aquelas informações que têm sentido para elas, mesmo sem saber muito bem ordená-las. Em outras palavras, a partir de carências os sujeitos podem encontrar informações que venham preencher essa lacuna. Não há dúvida de que esses dados passam a ser significativos, e a pessoa começa a gerar informações; operando, por vias inconscientes, a mente tenta acomodar os dados obtidos de forma a restabelecer o estado de equilíbrio rompido pela carência. Assim, ela tenta elaborar um projeto criativo, para solucionar o problema sentido, que pode ser um desenho, um texto literário, uma mensagem, uma poesia a ser divulgada à comunidade na qual ela está inserida. Pensando no ato criativo das pessoas, no modo como se estabelecem as relações dentro desse contexto, o método criativo sensível, associa usualmente às práticas de caráter artístico como artes, músicas, literatura e todas aquelas que acreditam que a criatividade pode converter-se em aquisição de conhecimentos. Esse método proporciona, segundo Bordini e Aguiar (1988, p.71).

[...] o exercício da intuição como forma imediata de conhecimento do mundo, bem como as habilidades de analisar, comparar, combinar, classificar e ordenar, efetuar inferências e, principalmente, extrapolações, vinculando essas operações intelectuais à ação física e à prática social, nos produtos criados.

\section{A S Ó CIO-POÉTICA}

A pesquisa sócio-poética foi proposta por Jacques Gauthier, a partir dos anos 1990 tendo como base o método do grupo-pesquisador herdado da "pedagogia do oprimido" de Paulo Freire. De acordo com Gauthier et al. (2001) seus fundamentos se apoiam em cinco pontos-chave: a importância do corpo como fonte de conhecimento; a importância das culturas dominadas e da resistência, das categorias e dos conceitos que elas produzem; o papel dos sujeitos pesquisados como co-responsáveis pelos conhecimentos produzidos; o papel da criatividade no aprender, no conhecer e no pesquisar e, a importância do sentido espiritual, humano, das formas e dos conteúdos na construção dos saberes. Essa forma de pesquisar "desterritorializa o saber acadêmico", procurando apoio em outros saberes a fim de compreender criticamente a realidade estudada em uma perspectiva de produção coletiva de conhecimento. Suas vivências têm sido experimentadas com bastante sucesso nas áreas de enfermagem e educação, tendo apresentado resultados muito ricos e contribuído para a melhor compreensão da realidade social estudada.

Na concepção de Gauthier et al. (1998, p.15), ao se optar pela pesquisa sócio-poética 
"estamos sempre interrogando o sentido das práticas e experiências dos grupos humanos; logo podemos somente encontrar respostas locais e parciais a nossas inquietações." Sua validação está no fato de que estamos no caminho do meio, entre os saberes espontâneos que os grupos têm da vida social (saberes que muitas vezes a ciência acadêmica ignora) e a crítica destes saberes, proporcionada pelo método do grupo-pesquisador. A técnica para a coleta dos dados se constitui em vivências onde todos os envolvidos participam coletivamente.

No campo da Ciência da Informação e da Biblioteconomia iniciamos, a partir de agosto de 2001, com os estudantes da disciplina Metodologia da Pesquisa em Biblioteconomia, uma vivência de pesquisa tendo por base a sócio-poética. Nosso intuito era de experimentar este novo modo de pesquisar no qual víamos a possibilidade de trabalhar as dificuldades que os alunos enfrentam com relação à compreensão do que seja a Biblioteconomia, a Ciência da Informação, o mercado de trabalho, a compreensão de seu papel enquanto alunos e futuros profissionais da informação. Também, procuramos trabalhar as questões de motivação dos alunos, de relacionamentos entre si, com os professores e funcionários, suas angústias, suas ansiedades e seus traumas em relação aos cursos ditos "nobres". A pesquisa tem como coordenadora a professora Virgínia Bentes Pinto, tendo a colaboração do monitor da disciplina e de todos os estudantes. Procuramos trabalhar em uma relação de afetividade e carinho a fim de que todos sentíssemos prazer na pesquisa e pudessem descobrir o valor de sua contribuição.

Iniciamos nossa vivência com uma técnica de relaxamento para que em seguida fosse possível construirmos nosso caminhar sócio-poético. O processo foi um caminho pautado nos temas vistos anteriormente e que vai do local ao global. Para tanto, nos apoiamos nos lugares geométricos propostos por Gauthier et al. (1998): a terra, os fluxos, uma gruta, um caminho, um poço, uma galáxia, um rio, uma trilha, uma estrada, um cume, um arco-íris. Através desses lugares, poderíamos trabalhar o imaginário do grupo pesquisador que forneceria suas impressões acerca das questões anteriormente apresentadas e, qual seria a sua relação com o curso e com a profissão. Em folhas de papel pardo escrevemos os lugares e em seguida cada participante escrevia suas impressões em tiras de cartolina e posteriormente a relação de cada impressão com o curso e com a profissão (Quadro 1).

A pesquisa continua em 2002 com os alunos que cursaram a disciplina Metodologia da Pesquisa em Biblioteconomia no primeiro e segundo semestres de 2001 e, também, com os alunos matriculados no primeiro semestre de 2002. As análises estão sendo construídas pelo grupo-pesquisador na perspectiva dialógica de Paulo Freire e polifônica de Mikhail Bakhtin, através das visões, da intuições, da análise e crítica de todos os envolvidos. Estas são as razões pelas quais ainda não está sendo possível apresentá-las nestas reflexões. No entanto, apresentamos algumas construções poéticas produzidas pelo grupo pesquisador.

Um dia fui surda, muda e cega. Minha cabeça não raciocinava. Hoje posso dizer que me curei, pois vejo, falo e enxergo. Minha cabeça, hoje também raciocina, cria e me motiva a querer cada vez mais. O remédio da minha cura foi o curso de biblioteconomia (Jaqueline - 5o Semestre).

Depois de ter tido uma visão mais ampla de tudo o que estamos enfrentando neste curso podemos ver que para nos sentirmos melhor é preciso que a gente se una e lute para levarmos o melhor de nós e da profissão para toda a sociedade, só assim todos vão passar a nos valorizar (Aluna do 5o semestre). 
Quadro 1. Espaços geomíticos do curso de Biblioteconomia.

\begin{tabular}{|c|c|c|}
\hline Lugar Geométrico & Impressão & Relação \\
\hline Terra & Planeta, lugar onde as pessoas vivem & Vida \\
\hline Gruta & Limites, escura, luta, busca & Pesquisa, caminhos, alternativas \\
\hline Trilha & Lugar incerto & $\begin{array}{l}\text { Alterar a imagem do curso e do pro- } \\
\text { fissional, responsabilidade, com- } \\
\text { panheirismo, determinação, garra, } \\
\text { aprendizagem }\end{array}$ \\
\hline Poço & Escuro, medo, sujo & Desmotivação, Comodismo, labirinto \\
\hline Galáxia & $\begin{array}{l}\text { Lutar pelo curso e pela valorização } \\
\text { profissional }\end{array}$ & Ir a luta para se fazer respeitado (a) \\
\hline Cume & Perspectiva & Sabedoria \\
\hline Arco-íris & Colorido, liberdade, conquistas, sucesso & $\begin{array}{l}\text { Educação continuada, Distante, va- } \\
\text { lorização }\end{array}$ \\
\hline Ponte & Liga os pontos, esforço, fim, fantasma & $\begin{array}{l}\text { Ligação entre curso e mercado, difi- } \\
\text { culdade, segurança }\end{array}$ \\
\hline Fluxo & Fluxos de idéias & $\begin{array}{l}\text { Lugar de investigação, egoísmo, } \\
\text { orgulho, medo }\end{array}$ \\
\hline
\end{tabular}

Fonte: Gauthier et al. (1998).

Só

cOm

Criatividade e

Interesse

cOnseguiremos

Progredir

POis

É

Tecnologia

Informação

Com

CApacidade profissional que venceremos no mercado de trabalho (Lucieuda - 5 o semestre)

\section{E N S IN A R E A PRE N DER: O "XIS" DA PESQUISA}

As mudanças que vêm se processando atualmente na sociedade, têm atingido todos os campos dos saberes, independentemente se ciências formalmente constituídas, como por exemplo, a física e a matemática até as chamadas pseudo-ciências como a homeopatia, quiromancia entre outras. A miscigenação dos campos faz-se necessário para que os domínios de conhecimento se fortaleçam na disciplinaridade (seja inter, ras ou multi). 
A partir da promulgação da Legislação das Diretrizes e Bases (LDB) da educação brasileira em 1996, as universidades estão sendo chamadas a implementar seus Projetos Políticos Pedagógicos e, que nestes, deve estar contemplada a inclusão dos Trabalhos de Conclusão de Cursos (TCC), como requisito para a conclusão dos cursos de graduação materializados nas chamadas monografias. Atrelada a esta decisão vem a necessidade do se fazer pesquisas nas universidades e, naturalmente, a exigência de uma matéria que possa contribuir para o desenrolar da ação pragmática da monografia. Daí a presença de disciplinas como: Metodologia Científica, Elaboração do Trabalho Intelectual, Pesquisa bibliográfica, Métodos e Técnicas de Pesquisa, entre outros nomes, em uma perspectiva do ensinar e aprender a pesquisar, estando aí o "xis" da questão.

A implantação de monografias de conclusão de cursos de graduação, independente se em Universidades Federais ou particulares, tem enfrentado muitos problemas até o aluno conseguir chegar à efetivação do ato monográfico. Suas trilhas, que poderiam ser percorridas em uma simbiose prazerosa e de grande contribuição para o aperfeiçoamento do jovem, passa a ser o seu "carma", daí o bloqueio. Mas por que será que isto acontece? Talvez a resposta esteja associada a quatro fatores.

Primeiro, é a falta da vivência (mínima) da pesquisa no ensino fundamental e médio. Nas escolas (quando possuem bibliotecas) e, nas bibliotecas públicas (quando existem nos municípios e estados), assim como em nossas casas, escuta-se e vê-se muitos alunos dizendo - vim fazer uma pesquisa da matéria tal, o professor mandou fazer uma pesquisa, tenho que fazer uma pesquisa para amanhã. E vão eles para a Pescópia (Pesquisa + cópia, criação nossa) de verbetes inteiros das enciclopédias, de passagens de livros ou outros documentos reais ou eletrônicos. Assim, a única vivência experimentada é o exercício dos dedos conduzindo o instrumento copiador: lápis, caneta, lapiseira, as teclas do computador ou o mouse, sem saber o que estão fazendo, e a história se repete.

No ambiente virtual, a "Pescópia" parece ter ficado mais fácil ainda, pois na cópia parcial ou total dos textos o desperdício de energia e tempo é menor, porém, a absorção do conteúdo fica cada vez mais comprometida e o discernimento do que seja o ato de pesquisar, sem alteração.

Segundo, porque o imaginário da pesquisa é a solidão, a dedicação exclusiva, é uma atividade pesada. Este imaginário é ratificado por muitos que consideram a pesquisa dissociada da vida do ser humano, como algo extra-vida humana. Goldenberg (2001) vem ao nosso encontro ao afirmar que " pesquisar não significa separar 'corpo, alma e mente', ao contrário, ela exige criatividade, disciplina, organização e modéstia, baseando-se no confronto permanente entre o possível e o impossível, entre o conhecimento e a ignorância".

Terceiro, porque a pesquisa nas escolas parece não apresentar vínculo com a prática docente dos professores, independentemente se estão no ensino médio, fundamental ou na universidade, ou ainda se são professores de história, geografia, biologia, química, literatura, matemática, ética, filosofia, economia, ou outra matéria.

Quarto, porque a matéria metodologia da pesquisa parece ser relegada a segundo plano nas escolas, inclusive sendo ministrada muitas vezes por pessoas que nunca experimentaram esta prática. Autores como Stenhouse (1975), Demo (1994), André (1995) são enfáticos nas suas análises sobre o fim da dicotomia professor $x$ pesquisador. A idéia básica parte do princípio que, cada classe seria um laboratório e o professor faria parte como membro da comunidade científica. Com esta prática poderíamos nos apropriar do conceito dialético de pesquisa, o que certamente contribuiria para a melhor compreensão deste domínio e, também, para a melhor forma de ministrar as disciplinas da área. 


\section{O NSIDERA ÇÕ ES FIN A IS}

Compreendemos que não é possível pensar ensino da pesquisa sem levar em conta o envolvimento dos atores deste processo: estudante, orientador e professor, principalmente de metodologia, para que as trilhas sejam permeadas por saídas mais prazerosas e sem muitos atalhos carregados de mangue e picadas de insetos.

Em outras palavras a pesquisa, é construída em "um verdadeiro labirinto onde é muito fácil alguém se perder, a menos que tenha

\section{REFERÊ N CIAS}

ANDRÉ, M.E.D.A. Etnografia da prática escolar. Campinas: Papirus, 1995. 123p.

BARBIER, R. A escuta sensível em educação. Cadernos ANPED, Belo Horizonte, n.5, p.187-215, 1993.

BAGNO, M. Pesquisa na escola: o que é, como se faz. São Paulo: Loyola, 2001. 102p.

BEILLEROT, J. La recherche: essai d'analyse. Recherche de Formation, Paris, v.9 p.17-31, Avril 1991.

BORDINI, M.G.; AGUIAR, V.T. Literatura, a formação do leitor. alternativas metodológicas. Porto Alegre: Mercado Aberto, 1988. 176p.

CABRAL, I.E. O método criativo e sensível: alternativa de pesquisa na enfermagem. In: GAUTHIER, J.H.M. Pesquisa em enfermagem: novas metodologias aplicadas. Rio de Janeiro: Guanabara Koogan, 1998. p.177-203.

DEMO, P. Pesquisa e construção do conhecimento. Rio de Janeiro: Tempo Brasileiro, 1994. p.255.

DERVIN, B. Users as research inventions: how research categories perpetuate myths. Journal of Communication, v.39, n.3, p.216-232, 1989.

GAUTHIER, J. A socio-poética: fundamentos teóricos, técnicas diferenciadas de pesquisa: um bom fio de Ariadne para se orientar. E esta é mesmo a palavra-chave: orientação" (BAGNO, 2001, p.14).

Independente ser na escola de ensino elementar, médio ou superior (graduação e pós-graduação), faz-se necessário que, no ato de pesquisar, o monstro Minotauro do medo, das angústias e quem sabe, dos traumas envolvidos na construção de seu imaginário, seja destruído pelo prazer holístico da atividade de investigar, onde o corpo, a mente e a alma não sejam desvinculados deste processo.

vivência. Rio de Janeiro: UERJ/DEPEXT/NAPE, 1996. 83p.

GAUTHIER, J.H.M. et. al. Pesquisa em enfermagem: novas metodologias aplicadas. Rio de Janeiro: Guanabara Koogan, 1998. 302p.

GAUTHIER, J.; FLEURY, R.M.; GRANDO, B.S. (Org.). Uma pesquisa socio-poética. Florianópolis: UFSC, 2001. 120p.

GOLDENBERG, M. $A$ arte de pesquisar: como fazer pesquisa qualitativa em Ciências Sociais. Rio de Janeiro: Record, 2001. 107p.

GURVITCH, G. Déterminismes sociaux et liberté humaine. Paris: PUF, 1955. 140p.

HUGHES, J. A filosofia da pesquisa social. Rio de Janeiro: Zahar,1983. 156p.

MINAYO, M.C.S. O desafio do conhecimento: pesquisa qualitativa em saúde. Rio de Janeiro: Hucitec, 1993. 80p.

SANTOS, B.S. Um discurso sobre as ciências. Porto: Edições Afrontamento, 1996. 198p.

SERPA, L.F.P. Ciências e historicidade. Salvador: [s.n.], 1991. 120p.

STENHOUSE, L. La investigación como base de la enseñanza. Madrid: Morata, 1975. 
